\title{
A DIMENSÃO ESTÉTICO-TRÁGICA DO PENSAMENTO DE NIETZSCHE E OS DESAFIOS PARA A EDUCAÇÃO
}

\section{LA DIMENSIÓN ESTÉTICO-TRÁGICA DEL PENSAMIENTO DE NIETZSCHE Y LOS DESAFIOS PARA LA EDUCACIÓN}

\author{
THE AESTHETIC-TRAGIC DIMENSION OF NIETZSCHE THOUGHT AND \\ CHALLENGES FOR EDUCATION
}

\author{
Lucinéia Aparecida FERREIRA $^{1}$ \\ Luciane NEUVALD ${ }^{2}$
}

\begin{abstract}
RESUMO: O texto objetiva discutir a dimensão estético-trágica do pensamento de Nietzsche, pois suas ideias são provocativas e vão além do bem e do mal. Ao pensar dessa forma, ele elabora uma crítica ao conhecimento, que não ocorre por meio de uma perspectiva epistemológica, já que a ciência é colocada sob suspeita, pela possibilidade de ocultar o caos em meio à superabundância e escapar do pessimismo. Nietzsche, ao considerar a arte como o eixo central de sua filosofia, propõe a transvaloração dos valores morais. As concepções educacionais que se baseiam exclusivamente na racionalidade pressupõem que o mundo deve ser conhecido e decifrado, já que as dificuldades e os sofrimentos consistem em obstáculos. A educação estético-trágica, por outro lado, propõe que o caos inerente à vida seja considerado como um elemento que potencializa e fortalece o ser humano.
\end{abstract}

PALAVRAS-CHAVE: Dimensão estético-trágica. Educação. Espírito livre. Nietzsche. Transvaloração de todos os valores.

RESUMEN: El texto tiene como objetivo discutir la dimensión estético-trágica del pensamiento de Nietzsche, ya que sus ideas son provocativas y van más allá del bien y el mal. Al pensar de esta manera, elabora una crítica del conocimiento, que no ocurre a través de una perspectiva epistemológica, ya que la ciencia es puesta bajo sospecha por la posibilidad de ocultar el caos en medio del exceso y escapar del pesimismo. El arte como eje central de su filosofía propone la sobrevaloración de los valores morales. Las concepciones educativas basadas exclusivamente en la racionalidad presuponen que el mundo debe ser conocido y descifrado, ya que las dificultades y los sufrimientos son obstáculos. La educación estéticatrágica, por otro lado, propone que el caos intrínsico a la vida se considere como un elemento que potencia y fortalece al ser humano.

PALABRAS CLAVE: Dimensión estético-trágica. Educación. Espiritu libre. Nietzsche. Sobrevaloración de todos los valores.

\footnotetext{
${ }^{1}$ Instituição: Universidade Estadual do Centro Oeste (UNICENTRO), Guarapuava - PR - Brasil. Dicente do programa de pós-graduação em educação. ORCID: http://orcid.org/0000-0003-0542-039X. E-mail: lucineiaffferreira@hotmail.com

${ }^{2}$ Instituição: Universidade Estadual do Centro Oeste (UNICENTRO), Guarapuava - PR - Brasil. Professora do curso de pedagogia e do programa de pós-graduação em educação. ORCID: https://orcid.org/0000-0002-15667030. E-mail: pmelo.pituba@gmail.com
} 
ABSTRACT: This paper aims to discuss the aesthetic-tragic dimension of Nietzsche's thought, since his ideas are provocative and go beyond good and evil. Thinking this way, he elaborates a critique of knowledge, which does not occur through an epistemological perspective, since science is placed under suspicion, by the possibility of hiding chaos amidst too many options and escaping pessimism. Nietzsche, believe art as central axis of his philosophy, proposes the overvaluation of moral values. Educational conceptions based only on rationality presupposes knowing and deciphering the world, because difficulties and suffering are barriers. Aesthetic-tragic education, on the other hand, proposes that intrinsic chaos in life be an element that empowers and strengthens the human.

KEYWORDS: Asthetic-tragic dimension. Education. Free spirit. Nietzsche. Overvaluation of all values.

\section{Introdução}

O modo como o pensamento lógico-racional foi desenvolvido ao longo da história do Ocidente é alvo da crítica de Nietzsche (2017), pois, na sua concepção, o aparecimento da figura de Sócrates marcou o início de uma cultura obcecada pela busca e aperfeiçoamento da verdade. Por outro lado, os gregos arcaicos, que viveram na fase anterior ao período socrático, eram capazes de lidar com a inteireza da existência e de construção da vida, tal como um artista produz sua obra de arte.

A ascensão da escola socrático-platônica expressa, para a concepção nietzschiana, a emergência de uma perspectiva que prioriza elementos da racionalidade e que tende a suprimir os lados obscuros do mundo: o erro ou o mal. Nietzsche não desenvolveu uma concepção epistemológica, mas realizou uma crítica ao conhecimento científico por meio da arte, tendo em vista sua característica não dogmática.

Do ponto de vista de Nietzsche (2003), a cultura do Ocidente foi produzida ao longo dos tempos a partir de valores antagônicos: bem e mal, verdade e erro. Esse tipo de oposição contribuiu para que importantes âmbitos da existência fossem elididos, em função da busca pela certeza, pela segurança e pelo conforto. Essa tradição histórica marca profundamente o modo de pensar e agir do homem ocidental.

Nietzsche (2003), em outra direção, propõe uma possibilidade artística que aponta a apreensão de todas as experiências humanas no mundo, de forma a incorporar os obstáculos e potencializar a formação. A valorização das misérias humanas e dos elementos considerados sombrios não significa pessimismo, pois a aceitação da existência em sua completude implica o amor ao destino e à condição trágica da vida, uma vez que ela se constitui de alegrias e misérias, as quais podem ser consideradas como possibilidades de crescimento humano. 
À luz desses pressupostos, este texto desenvolve um estudo introdutório, de cunho bibliográfico, sobre o pensamento de Nietzsche e de alguns de seus intérpretes, a fim de compreender a dimensão estético-trágica do pensamento do autor e os desafios para a educação. Para cumprir tal intento, o texto divide-se em três momentos.

O primeiro momento apresenta a noção de cultivo do espírito livre, que remete ao tipo humano vislumbrado por Nietzsche (2011), o qual se opõe ao animal de rebanho, que é atribuído pelo autor ao homem moderno, na medida em que este incorpora a fraqueza e a decadência promovidas pela sociedade ocidental. Sob essas condições, nega-se a vontade de potência afirmativa, caracterizada pela expansão, pelo crescimento, pela força e abundância.

O segundo momento discute a dimensão estético-trágica do pensamento de Nietzsche (2003), que explicita em que consiste tal dimensão e porque o autor opta por essa perspectiva teórica.

Por fim, o terceiro momento aborda a relação da dimensão estético-trágica com a educação, e evidencia a necessidade de uma perspectiva educacional que seja constituída para além das polarizações valorativas. A força, a coragem e a abundância de vida são as bases de uma possível pedagogia estético-trágica.

\section{O cultivo do espírito livre: o ser humano e a vontade de potência}

Conforme Nietzsche (2011), o espírito livre está na outra extremidade de qualquer ideia da modernidade europeia. O espírito livre assume essa condição porque está para além de culpabilidades e correntes morais; não possui o objetivo de que a humanidade seja nivelada; não busca o alívio das dores e do sofrimento, antes disso, busca o crescimento até as alturas. O espírito livre é sinônimo de ousadia e coragem. Para um espírito moralizado, o sofrimento é um veneno, mas para o espírito livre, o sofrimento é um tônico.

O homem, como ser indeterminado, deve cultivar a liberdade de seu espírito e aprender a lidar com sua inconstância, com sua imprevisibilidade e com sua incompletude. Essa atitude é proposta por Nietzsche (2017), para quem o homem moderno constitui-se em um animal de rebanho e necessita ser superado. Esse homem se caracteriza por uma tendência que é a busca da certeza e da segurança, cujos aspectos não condizem com o cultivo do espírito livre.

Nietzsche (2011) vai às últimas consequências de sua crítica acerca do homem moderno, afirmando que o espírito livre não deve se apegar às pessoas, à pátria e à ciência. $\mathrm{O}$ 
espírito que se pretende livre não deve se apegar, inclusive, ao desapego que lhe é característico:

Não se apegar a nenhuma pessoa, fosse ela a mais cara - [...]. Não ficar ligado a uma pátria, [...]. Não se deixar prender por um sentimento de compaixão, [...]. Não se apegar a uma ciência, ainda que nos aparecesse sob o aspecto mais sedutor, com descobertas preciosas que parecessem reservadas para nós. Não se prender a seu próprio desapego, a esse afastamento voluptuoso do pássaro que foge para os ares, levado por seu vôo, para ver sempre mais coisas acima dele - é o perigo daquilo que plana (NIETZSCHE, 2011, p. 57, grifos nossos).

Em “Além do Bem e do Mal”, Nietzsche (2011) é contundente em sua crítica ao animal de rebanho. O homem que adere ao rebanho é aquele que se encontra domesticado, apequenado, em suma, moralizado até as últimas consequências. Desse modo, em Nietzsche, o homem moderno (o último homem) faz parte do rebanho no sentido de que a modernidade ocidental significa a massificação humana. $\mathrm{O}$ animal de rebanho significa fraqueza e decadência, no sentido de que busca se fixar em um determinado ponto, busca encontrar uma essência, que é permanente e estática. Por outro lado, o autor valoriza a força e a saúde, que são próprias do espírito livre, ou seja, do homem como um complexo de forças, um ser indeterminado e dinâmico, que compreende a vontade de potência como afirmação da existência.

A vontade de potência constitui tudo o que existe no mundo e, na concepção de Nietzsche (2017), deve ser o critério de avaliação da vida. Ela manifesta-se em todas as coisas, tanto nas fortes quanto nas fracas; deve ser a instância última de apreciação porque refuta a ideia de que os valores morais possuem origem num além-mundo (na metafísica ou na religião). Assim, a filosofia mais amadurecida de Nietzsche critica as oposições ou dicotomias valorativas, pois sua concepção de mundo indica que a vontade de potência é dinâmica e que não há um fundo verdadeiro a ser buscado. A vontade de potência, portanto, não é uma essência fixa; ela é a manifestação das forças.

Para Nietzsche (2017), a mais alta vontade de potência imprime ao devir o caráter do ser. A origem do devir está nos sentidos, assim, o devir é “[...] considerado como invenção, como querer, como negação de si, como vitória sobre si mesmo: não um sujeito, mas uma ação, uma avaliação criadora, nada de 'causas' e nem de 'efeitos”' (NIETZSCHE, 2017, p. 390).

O devir inerente à vontade de potência constitui-se em um meio de expansão da vida, de sua multiplicidade de sentidos, ao invés das concepções polarizadoras. A interpretação 
nietzschiana de mundo considera o devir e, assim, pode contribuir com a libertação do homem que se acha preso às amarras envenenadoras da herança moral.

No horizonte dessa perspectiva, a dimensão estético-trágica significa enfrentamento, cultivo da força e a transvaloração dos valores impostos como hegemônicos pela tradição de muitas das sociedades do Ocidente. Dessarte, o espírito livre aceita seu destino e abraça a existência da forma como ela se apresenta.

Entretanto, a ideia de destino deve aqui ser concebida sob a noção de amor fati, que significa amor ao destino. Por isso, o cultivo do espírito livre relaciona-se visceralmente com a coragem, a saúde e a força. A aceitação do destino não é concebida, aos olhos de Nietzsche (2003), no sentido de conformismo, mas no sentido de que o espírito livre enfrenta a vida e assume que os valores morais são humanos, portanto, são terrenos e passíveis de transformação. Não se pode mais recuar frente ao destino. Do mesmo modo, o homem assume sua responsabilidade sobre a vida e deixa de se escorar em instâncias metafísicas ou religiosas.

O cultivo do espírito livre exige uma interpretação de mundo que implica o entendimento de que o estado atual de um homem se configura apenas em um estágio passageiro. Para Viesenteiner (2014), enquanto houver vida, novas vivências podem se apresentar e alterar a trajetória do ser humano no mundo. Trata-se de uma transformação contínua. A relação do ser humano com o tempo é, assim, crucial para a perspectiva nietzschiana. O presente nunca é alcançado plenamente.

Nesse sentido, Nietzsche (2011), em sua crítica ao homem moderno como animal de rebanho, indica que o cultivo da liberdade do espírito significa o jogo mais perigoso que o ser humano poderia enfrentar. Para ele, quando o destino de um homem caminha para a independência, tal jogo é necessário e fundamental. Antes de qualquer coisa, o homem deve se colocar à prova, mas no intuito de ele mesmo perceber sua força; o homem é testemunha de si mesmo, e não deve se preocupar com juízos externos.

Assim, de acordo com Nietzsche (2003), quando o homem cultiva suas forças abundantes, que se baseiam no critério da vontade de potência, ele pode crescer criativa e frutuosamente. Esse crescimento, que consiste em uma espécie de amadurecimento conquistado ao longo de suas vivências, contribui para que ele desenvolva recursos que o tornem capaz de existir sob o ensinamento do eterno retorno, ou seja, cada instante é vivido como se pudesse retornar eternamente. O momento presente não é considerado uma maldição; para o espírito livre, o agora é uma dádiva. 
No entendimento de Nietzsche (2011), o homem fraco não cultiva seu espírito e deseja avidamente a fraqueza alheia. Ao contrário dele, o homem forte é abundante e quanto mais força cultiva, mais responsável se torna pela sua existência e pela criação de valores arautos de uma moral que cultiva a liberdade do espírito e se opõe à moral prescritiva, uniformizadora e voltada para o autodomínio.

Esses pressupostos ajudam a compreender a escolha nietzschiana pela dimensão estético-trágica e pelos gregos helênicos.

\section{A dimensão estético-trágica em Nietzsche}

A opção de Nietzsche (2004) pela dimensão estético-trágica situa-se no âmbito da problemática a respeito da ciência, cuja compreensão não ocorre no terreno científico, pois só um deus artista pode se desvencilhar da necessidade, colocar a moral à prova e posicionar-se da mesma maneira diante do bom e do ruim. A ciência é colocada em questão na medida em que o autor suspeita que ela oculta o caos que existe em meio à superabundância; também suspeita que ela seja uma forma de escape ao pessimismo, uma forma de covardia e de falsidade.

Em “A Origem da Tragédia”, Nietzsche (2004) escrevera: “[...] declaro que, por convicção profunda, considero na arte a missão mais elevada e a atividade essencialmente metafísica da vida humana [...]" (NIETZSCHE, 2004, p. 18). Nessa passagem, publicada originalmente em 1871, Nietzsche estava influenciado, em demasia, por Richard Wagner, Arthur Schopenhauer e Immanuel Kant, portanto, pensava em termos de uma "metafísica de artista".

Após romper a amizade com Wagner e, sobretudo, amadurecer sua crítica em relação às filosofias de Schopenhauer e Kant, Nietzsche (2011) não mais compreende a arte como atividade metafísica. Nos períodos intermediário e amadurecido do desenvolvimento de seu pensamento filosófico, a arte, conforme Machado (2017), não é tomada de forma explícita em seus escritos; a crítica da moral se torna a discussão central da filosofia nietzschiana. Esse descolamento se justifica porque a arte é o pano de fundo para o seu projeto de transvaloração de todos os valores. Dito de outro modo, Nietzsche propõe a transvaloração dos valores morais ao considerar a arte como o eixo central de sua filosofia. Desse modo, a arte não possui mais a conotação metafísica da juventude nietzschiana. Em 1882, quando da publicação de "A Gaia Ciência", o autor escreve no aforismo 107: "Enquanto fenômeno estético, a existência ainda nos é suportável e a arte nos dá os olhos, as mãos, sobretudo a boa 
consciência, que é necessária para poder fazer de nós mesmos este fenômeno" (NIETZSCHE, 2003, p. 103).

Portanto, a existência é a obra, o homem é o artista. A vida como obra de arte: eis o aspecto vital a ser compreendido. A existência é estético-trágica; portanto, ao ser humano cabe a tarefa de criar valores. Por isso, a apologia da arte não se desvincula da crítica da moral. Mais adiante, no mesmo aforismo "A nossa última gratidão para com a arte", evocado no parágrafo anterior, Nietzsche explicita:

Seria para nós um recuo - e precisamente em virtude da nossa suscetível integridade - cair inteiramente na moral, e tornarmo-nos, em função das superseveras exigências que nos fazemos neste ponto, monstros e espantalhos virtuosos. É preciso que possamos também nos colocar acima da moral; e não somente com a inquieta rigidez daquele que receia a todo o instante dar um passo em falso e cair, mas com o à vontade de alguém que pode flutuar e zombar acima dela! Como poderíamos nos privar da arte e do louco?... E, enquanto mantiverdes alguma vergonha de vós próprios, não sereis ainda capazes de ser dos nossos (NIETZSCHE, 2003, p. 103-104, grifo do autor).

Nesse sentido, o projeto mais ambicioso de Nietzsche não se relaciona à arte como atividade específica, mas como atitude assumida diante da vida. Conforme Machado (2017), a arte trágica faz emergir a possibilidade de que o homem suporte a vida; mas, além disso, ela é o grande estimulante da existência. Portanto, sob a perspectiva nietzschiana, a arte não pode ser compreendida como um narcótico, pois ela é um tônico.

A criação de novos valores, para Machado (2017), diz respeito a uma criação artística. Nietzsche criticou a vontade de verdade por entendê-la como vontade negativa de potência, ou seja, como força de conservação. A criação de novas condições de vida implica a interpretação artística dos impulsos. Nietzsche pretende que o próprio pensamento humano seja inundado por uma onda dionisíaca. Assim, a principal proposição nietzschiana consiste em:

[...] considerar a arte trágica como modelo de um pensamento e uma atividade que, não mais dominados pela vontade de saber, expressem uma vontade afirmativa de potência. O "espírito livre" é aquele que reinventa o real, que transfigura a vida (MACHADO, 2017, p. 149-150).

A busca pela verdade não pode ser consentânea com uma educação voltada ao cultivo do espírito livre. A escola, compreendida como a instituição que deve socializar o pensamento científico, não se relacionaria, portanto, à dimensão estético-trágica da vida. A educação que está atrelada aos confortos da verdade é uma educação moralizadora. 
A dimensão estético-trágica não crê na estabilidade tão prometida pelas concepções otimistas, mas compreende a inconstância existencial que se manifesta no fluxo das forças, na vontade de potência. Além disso, Silva (2011) destaca que o "jeito estético-trágico" não se identifica com o pessimismo do sofredor, isto é, não faz a apologia de um sofrimento imobilizante. Sob essa perspectiva, a arte trágica se identifica com a atitude do pessimismo dionisíaco, no qual é possível fortalecer-se por meio do sofrimento.

O pessimista dionisíaco é o espírito livre, que cultua a imoralidade e vive sob o ensinamento do eterno retorno. Ao aceitar a vida como ela se apresenta, ao amar o seu destino, o pessimista dionisíaco não se rende, pois, enquanto cultiva a liberdade de seu espírito, ele se torna forte o suficiente para criar novos valores. O otimista, identificado como o homem moderno ocidental, mostra-se enfraquecido, envenenado pela moral e entende que, somente sob as condições ideais, poderia exercer domínio sobre a vida.

\section{Diálogos entre a dimensão estético-trágica e a educação}

Para Nietzsche (2011), a incapacidade de lidar com a incerteza representa a morte: significa que aquele que busca a certeza está fatigado e desesperado; ao contrário, o homem ávido pela vida é aquele que lida com um mundo que é composto pela verdade, mas também pelo erro. Assim, o ser humano forte, realmente livre, é capaz de compreender a tragicidade da existência humana: o mundo é composto pelo bem e pelo mal. A partir dessa compreensão, o homem passa a lidar com o caos da vida de forma sadia: o devir não é mais um peso.

Ainda segundo Nietzsche (2011), a Europa de seu tempo discutia com muita dedicação o problema do "mundo real" e do "mundo das aparências", pois praticamente todos estavam afoitos pela "vontade do verdadeiro". O autor afirma que, em certos casos, poderia até existir uma genuína preocupação com a dita "vontade do verdadeiro", que ainda representaria uma aventura; pois, a busca extravagante pela verdade a todo custo significa, em última instância, “[...] o orgulho metafísico de uma sentinela perdida que prefere um punhado de 'certeza' a toda a nossa carrada de belas possibilidades" (NIETZSCHE, 2011, p. 26). Desse modo, para a perspectiva nietzschiana, o homem foi formado, ao longo da história ocidental, para lidar mais facilmente com a fé em ideias asseguradas, mesmo que elas representem um nada, a lidar com as múltiplas possibilidades incertas.

Nietzsche (2011) levanta a hipótese de ser o primeiro dos filósofos a correr o risco de questionar o lugar privilegiado da verdade. Ao situar a vida no centro dos critérios de apreciação, o autor demonstra um dos aspectos mais importantes de seu pensamento, pois, 
"Admitir que a mentira é uma condição vital, isso é certamente opor-se de forma perigosa às avaliações habituais; uma filosofia que o ousasse, lhe bastaria para colocar-se desse modo além do bem e do mal" (NIETZSCHE, 2011, p. 22).

Quando Nietzsche (2011) vislumbra uma filosofia que se eleve acima do bem e do mal, ele pensa na elaboração de uma crítica ao conhecimento, não por meio da constituição de uma perspectiva epistemológica, mas a partir da compreensão do conhecimento relacionado à moral. Arrisca-se a afirmar que, grosso modo, para Nietzsche (2003), tanto na filosofia clássica quanto na ciência moderna, a ideia de verdade se relaciona com a ideia de bem; do mesmo modo, o autor sugere que o erro remete ao mal. Nesse sentido, é necessário ir além do bem e do mal: o caminho desenhado por Nietzsche vê, na arte trágica, a potencialidade que faz o homem ser abundante de vida.

Então, de acordo com Hardt (2013), a perspectiva estético-trágica nietzschiana parte da crítica ao homem moderno ocidental, que deve ser superado. A ciência, em sua insana busca pela verdade, instituiu o pensamento racional como a marca maior de sofisticação das sociedades. O problema consiste no fato de que essa atitude racional encara o mundo com a intenção de corrigi-lo. Consequentemente, as concepções educacionais que se baseiam exclusivamente na racionalidade partem do pressuposto de que o mundo deve ser conhecido e decifrado; as dificuldades e o sofrimento são compreendidos como obstáculos que devem ser desviados. Os seres humanos educados a partir dessa ótica são encorajados a conhecer os problemas da realidade para eliminá-los. A educação estético-trágica, por outro lado, propõe que o caos inerente à vida seja considerado como um elemento que potencializa e fortalece o ser humano.

Para afirmar a perspectiva estético-trágica, segundo Hardt (2013), é necessário transvalorar as concepções polarizadoras, que se apresentam como "salvadoras", mas que, em última análise, são morais. A essência racional nasce com a opressão dos impulsos naturais e, consequentemente, desqualifica a abundância da vida cultivada pelos gregos trágicos.

A pedagogia estético-trágica implica disciplina para o corpo, para o espírito; porém, não há rigidez, respostas fechadas. A prioridade consiste no processo de descoberta e não no resultado. A curiosidade deve ser guia importante no desenvolvimento das relações de ensinoaprendizagem (HARDT, 2013). Cultivar o espírito livre significa transformar-se continuamente. Por isso, antes de buscar respostas, Nietzsche (2011) propõe a investigação dos pressupostos. A desconstrução de fundamentos teóricos e da segurança por eles proporcionada traduz uma marca importante da perspectiva estético-trágica. Essa desconstrução estimula o pensamento e não diz respeito exclusivamente ao resultado de um 
problema, mas relaciona-se ao processo, que contribui para fortalecimento humano (HARDT, 2013).

Silva (2011) destaca que, historicamente, o "jeito racional” de ser é identificado com uma proposição otimista; pois, o pensamento racional, que é entendido aos olhos de Nietzsche como contaminado pela moral, liga-se a questões altruístas, progressistas, evolucionistas. Esse modo de conceber o mundo supõe que os impulsos naturais se ligam à irracionalidade e ao pessimismo paralisante. O "jeito racional" representa o bem, e o "jeito estético-trágico" representa o mal. Dessarte, o jeito racional constitui as bases para teorias que demonstram “[...] uma aparência ativa, transformadora e revolucionária” (SILVA, 2011, p. 110).

Ainda conforme Silva (2011), a perspectiva estético-trágica propõe que o processo de contínua transformação humana lida com a realidade como ela se apresenta, e não realiza juízos de valor. É importante encarar e enfrentar o mundo real, com aquilo que é possível sob as condições reais. Não se trata de desconsiderar as limitações impostas pelo meio social ou de contribuir com processos de desigualdade, mas de priorizar e desenvolver "[...] criteriosos estudos e projetos-pedagógicos sensíveis e respaldados pelas seguintes áreas do conhecimento: a Psicologia, a Sociologia, a Política, a Administração e a Filosofia" (SILVA, 2011, p. 118).

Segundo Nietzsche (2003), o ser humano necessita se fortalecer e se tornar capaz de acolher o agora, exatamente como ele emerge das circunstâncias da existência, sem a avidez de criar subterfúgios para escapar de determinada atitude ou situação. Não há uma busca exterior pelo crescimento. Antes de qualquer coisa, a força necessita ser cultivada a partir do próprio homem, já que ela nasce de seu âmago, de sua vida. Entretanto, o espírito livre é sinônimo de cultivo; por isso, só pode ser conquistado quando tomado como uma arte. Desse modo, a dimensão estético-trágica da formação é construída quando se paga o preço "[...] de um paciente exercício e de um trabalho de todos os dias" (NIETZSCHE, 2003, p. 149).

O ser humano fortalecido possui mais condições de aprender, de explorar e de cultivar a curiosidade. A aprendizagem não se restringe ao professor; pode ir além dele, pode contribuir para que o aluno crie asas e deseje ir sempre além. A pedagogia estético-trágica busca delinear um modelo formativo em que o aluno aceite o caos como componente do mundo, e que aprenda a lidar com ele de modo potente. O sofrimento só pode ser extinto num mundo ideal, metafísico. No mundo real, o sofrimento sempre existirá; e, a partir dessa constatação, a pedagogia estético-trágica contribui para que o aluno enfrente a frustração e veja nela um caminho para o crescimento. Ao passo que o ser humano se fortalece, a dor é 
acolhida de modo sadio; o sofrimento não é considerado o oposto do prazer, pois, segundo Nietzsche (2003), ambos são registros da vontade de potência.

Assim, a "Pedagogia do Ressentimento", conforme a denominação de Silva (2011), com o intuito de ser complacente, de aliviar o sofrimento, não visualiza a formação do espírito livre em longo prazo; ela age como um paliativo, no sentido de que acalma a dor no instante determinado, mas não cura o doente, que se torna cada vez mais ressentido. A supressão da paixão e o silêncio da vontade são manifestações da Pedagogia do Ressentimento, que não aceita a manifestação dos instintos porque não é capaz de organizar o caos. A Pedagogia do Ressentimento volta sua atenção sempre ao outro, ao que é exterior.

Para Hardt (2013), é urgente o questionamento das totalidades. A autora destaca que a política educacional se desenvolveu, hegemonicamente, com o objetivo de adequar, enquadrar e padronizar. O jeito racional visa à organização de currículos e instrumentos avaliativos que aderem ao "oficial". A formação que se efetiva insere o aluno no mercado de trabalho de forma abrupta, ou seja, carente da compreensão de sua própria condição existencial. Mais importante do que pensar em conteúdos específicos, no primeiro momento, a pedagogia estético-trágica considera necessário o entendimento da relação entre escola, sociedade e cultura, para, a partir daí, levantar a questão dos instrumentos necessários para a elaboração de métodos pedagógicos.

\section{Considerações finais}

A perspectiva estético-trágica, para além da elaboração de uma proposta pedagógica, convida o ser humano a reinterpretar sua existência em sua relação com o tempo. A vida humana é marcada pelo traço da inconsistência e da impermanência; por outro lado, ela é finita. Diante da negação da expectativa de um além-mundo, a existência não pode ser desperdiçada ou depreciada. A existência deve ser aproveitada e explorada intensamente. Cada instante efêmero compõe a grande obra dramática da vida. Por isso, não há espaço para arrependimentos. Há espaço apenas para a apreciação da inteireza e da beleza do sentido estético-trágico. Viver como se cada segundo pudesse retornar eternamente: eis a lição a ser apreendida. Fica o convite para que os grandes paradigmas educacionais sejam repensados: diga-se sim à vida e desconstruam-se os enquadramentos e padronizações impostos pelas perspectivas polarizadoras que levam ao adoecimento. 
Dessa forma, a educação na perspectiva estético-trágica estimula a descoberta e o pensamento. Ela não se prende a construções totalizadoras e niveladoras, mas se coloca para além do bem e de mal.

O caminho do espírito livre não busca a segurança da verdade ou do sentimento moral de bem. $\mathrm{O}$ espírito fortalecido sabe que o erro e o mal também constituem o mundo; por isso, a principal de todas as colocações da dimensão estético-trágica da formação implica o entendimento da vida como princípio formativo. A vida em sua inteireza, mesmo que dolorosa, deve ser encarada corajosamente.

O ser humano que compõe sua vida esteticamente não pode ser educado a partir de uma perspectiva excessivamente racional. A razão, para Nietzsche, é insuficiente para explicar o mundo. Por isso, a compreensão da noção de vivência pode ser alternativa no processo da vida. As vivências simplesmente emergem das circunstâncias existenciais e podem constituir um frutuoso processo formativo. De acordo com Viesenteiner (2014), as vivências não são planejadas; elas ocorrem de forma alternada, inesperada, numa relação imediata entre homem e mundo. Além disso, cada ser humano, singularmente, pode atribuir significados próprios às vivências. A composição de uma vida, do ponto de vista estéticotrágico, portanto, aceita o fluxo do devir.

O fluxo do devir se expressa no homem e no mundo. Nietzsche entende que o princípio constitutivo de tudo é a vontade de potência. A vida se move dinamicamente, age, explora, se manifesta sem cessar. Os instintos vitais se movimentam no seio do universo e do homem. As perspectivas polarizadoras buscaram oprimir os instintos, que foram rebaixados à condição de valor inferior. Nietzsche propõe a transvaloração das oposições valorativas. Desse modo, os instintos são aceitos como manifestação da vontade de potência.

O homem fortalecido, que aprende a lidar com seus instintos, aprende a lidar com o caos do mundo. A força dionisíaca não é negada, ela é acolhida. As perspectivas educativas alicerçadas na dimensão estético-trágica não buscam condições perfeitas para a formação humana. Independentemente de ordem social, a questão a ser levada em conta é a condição trágica do homem no mundo. A dimensão estético-trágica, portanto, não busca corrigir a realidade, não impõe uma solução ao mundo; antes disso, ela propõe que o ser humano se reconheça e se conheça, em nome de seu crescimento.

A educação estético-trágica se baseia na existência, e não em uma concepção idealista de ciência. Os conhecimentos não devem ser tomados, mas produzidos; o processo é fundamentalmente estético. Os valores impostos devem ser questionados para que o homem livre seja capaz de criar valores próprios, singulares. E esse fato não significa que as 
condições sócio-políticas devem ser ignoradas. Ao contrário, homens fortalecidos e conscientes de sua condição abrem a possibilidade de que circunstâncias de vida mais abundantes sejam criadas. A vida cultivada com abundância é uma forma de resistência ativa frente ao mundo atual.

Nessa direção, uma possível pedagogia estético-trágica nietzschiana deve considerar o aluno e a escola a partir de um ponto de vista concreto e terreno. As dificuldades não devem ser consideradas como obstáculos, elas são possibilidades de crescimento. O aluno não deve ser poupado do sofrimento, já que uma das condições mais importantes do processo de conhecimento é a capacidade de lidar com a frustração e com a dor. A existência depende, em certa medida, da forma como se lida com ela. O sofrimento que brota do caos do mundo não pode ser um elemento que tenda a paralisar o crescimento, ele deve ser um tônico que aumenta ainda mais a potência do homem em sua relação com os outros homens.

A partir de uma visão de mundo estético-trágica, a educação e a escola se baseiam na vida. A preocupação central deve consistir na restauração da relação de responsabilidade do homem com sua existência. Não há mais escoras metafísicas, não há possibilidade de um mundo mágico e ideal. A vida ocorre aqui, agora e sem pedir autorização. Cada instante deve ser apreciado no sentido de imprimir a noção de eternidade; portanto, não se pode pensar de forma opositiva, polarizadora. As dicotomias (verdade e erro, bem e mal) não são consentâneas com a pedagogia estético-trágica, pois esta não deseja julgar. A educação nietzschiana é agregadora, acolhedora, mas não piedosa. Nesse sentido, o tipo de formação proposta por Nietzsche é um desafio a ser colocado no horizonte.

\section{REFERÊNCIAS}

HARDT, L. S. A educação em Nietzsche e o enfrentamento das totalidades. Revista Educação, Porto Alegre (impresso), v. 36, n. 3, p. 344-351, set./dez. 2013.

MACHADO, R. Nietzsche e a Verdade. 3 ed. rev. Rio de Janeiro/ São Paulo: Editora Paz e Terra, 2017.

NIETZCHE, F. A gaia ciência. 2. ed. São Paulo: Editora Martin Claret, 2003.

NIETZCHE, F. A origem da tragédia. São Paulo: Centauro, 2004.

NIETZCHE, F. Além do Bem e do Mal: prelúdio de uma filosofia do futuro. 3. ed. São Paulo: Editora Escala, 2011.

NIETZSCHE, F. Vontade de Potência. Petrópolis, RJ: Vozes, 2017. 
SILVA, S. P. da. Pedagogia do Ressentimento: o otimismo nas concepções e nas práticas de ensino. Revista Brasileira de Estudos Pedagógicos. Brasília, v. 92, n. 230, p. 107-125, jan./abr. 2011. Disponível em: http://rbep.inep.gov.br/ojs3/index.php/rbep/article/view/2923. Acesso em: 10 abr. 2019.

VIESENTEINER, J. L. O homem como uma somatória unitária de Erlebnisse (vivências) em Nietzsche. Revista Filosofia e Educação: dossiê Nietzsche e a educação, Campinas, v. 6, n. 1, p. 76-94, fev. 2014. Disponível em:

https://periodicos.sbu.unicamp.br/ojs/index.php/rfe/article/view/8635386/3179. Acesso em: 15 mar. 2019.

\section{Como referenciar este artigo}

FERREIRA, Lucinéia Aparecida; NEUVALD, Luciane. A dimensão estético-trágica do pensamento de Nietzsche e os desafios para a educação. Revista Ibero-Americana de Estudos em Educação, Araraquara, v. 15, n. 2, p. 333-346, abr./jun. 2020. e-ISSN: 19825587. DOI: https://doi.org/10.21723/riaee.v15i2.12840

Submetido em: 15/082019

Revisões requeridas: 20/10/2019

Aprovado em: 20/12/2019

Publicado em: 20/02/2020 